\title{
LANGUAGE DISORDER IN A CASE OF KORSAKOFF'S SYNDROME
}

\author{
BY \\ P. R. F. CLARKE, MARIA WYKE, and O. L. ZANGWILL \\ From the Psychological Laboratory, the National Hospital, Queen Square, London
}

In 1935, Curran and Schilder drew attention to the incidence of a peculiar language disorder in cases with acute cerebral disturbances of traumatic or toxic origin. This disorder comprised misnaming, paraphasia, discursive and incoherent speech, and in some cases bizarre forms of verbal expression reminiscent of schizophrenia. Although the phenomena were ascribed in part to focal dysphasia, the authors commented on their similarity to certain types of language derangement occurring in the primary psychoses. Following Kleist $(1914,1934)$, they were led to place emphasis on the probable role of cerebral dysfunction in the genesis of language disorders in general.

In studies of post-traumatic confusional states undertaken during the war, Paterson $(1942,1944)$ was likewise impressed by the frequency of paraphasic speech disorders. He pointed out that although not all confused patients present a disturbance of speech, in those who do the picture differs in no essential way from that shown in cases of focal lesion without confusion, e.g., in jargon aphasia. Indeed in several of his cases clear-cut dysphasic residua long outlasted the acute confusional state. At the same time, it was suggested by Zangwill (1945) that the speech disorder in certain of Paterson's cases appeared to transcend an ordinary dysphasia and to involve an underlying derangement of the thought processes.

More recently, Weinstein and Kahn (1952) have devoted a paper to paraphasia in organic brain disease. Their observations are based on a series of 30 cases in which misnaming and other peculiarities of language were prominent. These disturbances, they point out, never occurred in isolation and were always associated with disorientation, denial of illness, and related symptoms of general organic type. The intracranial lesions consisted mainly of deeply situated or bilateral tumours, and aneurysms with subarachnoid haemorrhage; in nearly all cases the E.E.G. showed bilateral diffuse delta wave activity. The authors argue that the language disorders observed in their patients differ in important respects from those ordinarily met with in aphasia. For instance, words are not garbled and the rhythm of speech is normal. Further, misnaming was commonly referable to concomitant disorders of perception and orientation, and did not necessarily presuppose derangement within the sphere of language itself. Emphasis is also placed on the role of motivational factors, more especially those presumed to govern denial of illness. In conclusion, the authors argue that paraphasia in cases of organic brain disease should not be classed as an aphasic disorder referable to a focal lesion of the dominant hemisphere. It is to be regarded as the manifestation of a more general change in behaviour, in which altered patterns of perception and motivation play an important part.

In the analysis of confusional states it is obviously important to ascertain whether, and if so to what extent, focal signs and symptoms contribute to the overall picture. Although the attempt made by Paterson (1944) to explain confusion as a mere? aggregate of focal signs may well appear too atomistic, the conception of a global organic reaction-type advanced by Weinstein and Kahn (1952) undoubtedly goes too far in the opposite direction. As Paterson has pointed out, the confusional state is always an individual affair and shows very considerable variation from case to case. In particular, by no means all confused patients exhibit paraphasic speech and the latter does not appear obviously related to the depth or severity of confusion. Further, defects of orientation (Paterson, 1944) and denial of disability (Critchley, 1953; Brock and Merwarth, 1957) are often particularly prominent in cases in which the lesion principally involves the parietal lobes. It might therefore seem probable that both general and local changes in cerebral function contribute to the confusional state and that these, in combination, determine the incidence of paraphasia. At all events, one may suggest that fuller analysis of language and its disorders may throw light on the psychology of confusional states.

We propose in the present paper to attempt a preliminary analysis of the disorders of thought and 
language encountered in a case of Korsakoff's syndrome. It is hoped first, to determine whether the disorders in question are or are not referable to focal dysphasia; and secondly, to ascertain their relationship to concomitant changes in other spheres of psychological function.

\section{Case Report}

N. H. (Case No. 66352), a British Railways clerk, aged 62, and right-handed, was admitted under the care of Dr. Purdon Martin with complaints of episodic double vision, weakness in the legs, and numbness and coldness in the fingers of both hands of six months' duration.

One week previously, he had begun to "wander" in his mind, talking of the past and claiming to have recently seen his parents and other relatives long dead. He had become sleepy and difficult to rouse. There was also a history of recent loss of appetite, and of longstanding alcoholism.

On examination, the patient was facile, euphoric, and much given to confabulation. His speech was remarked to be nonsensical on occasion. He was disorientated in all spheres, believing himself to be in a flat in the vicinity of a hospital and the other patients to be railway workers. He gave the day (Monday) as Friday and the month (June) as May. His general knowledge and recent memory were very poor and insight was completely lacking.

On neurological examination, the main findings were unequal pupils, the right being slightly larger than the left, and some nystagmus, with impaired conjugate deviation in all directions. Convergence, on the other hand, was relatively well preserved. There was some loss of muscle power in the distal parts of the limbs but the most striking finding elsewhere was extreme tenderness of the muscles, with peripheral impairment of all forms of sensation. The tendon reflexes were uniformly diminished.

A diagnosis of alcoholic peripheral neuropathy with Wernicke's encephalopathy was made and some of the symptoms gradually settled down with large doses of B group vitamins. The eye signs were the first to clear; several weeks later the patient was again ambulatory and made few complaints of paraesthesiae. The results of liver function tests were relatively normal, but a histamine test meal revealed the absence of free acid in the stomach.

The patient was first seen in the Psychological Department two weeks after admission and thereafter reexamined at regular intervals until discharge.

He was at first completely disorientated for place and person, commonly believing himself to be in his usual place of work or at a clinic near his home. On one occasion, however, he thought he was on a Channel steamer bound for France. Persons were consistently misidentified in the light of his prevailing disorientation. Memory for recent events was virtually nonexistent and the patient confabulated freely. He showed also a patchy retrograde amnesia extending over some 10 years before the onset of the illness, though without clear-cut boundaries. His mood was in general euphoric, though this became less marked during the last few weeks in hospital, when the patient also regained some measure of orientation. He was facile and totally without insight, denying that he was ill or that his memory was in any way affected. In all these respects his mental state approximated to that of the classical Korsakoff psychosis.

Although the patient's speech appeared essentially normal in ordinary conversation, a curious paraphasic disorder was in evidence during the earlier stages of the illness. This was brought out most strikingly when the patient was asked to name objects, define words, explain proverbs or to undertake kindred tasks implying some measure of directed thinking (see below). There were also signs of a minimal defect in comprehension of speech at this time. Although the patient's hearing was in no way defective, he commonly asked for questions to be repeated and it was sometimes apparent that he had not fully grasped their import. Occasionally, he appeared completely at a loss for the meaning of a common word. He was, however, able to write with reasonable adequacy and showed no obvious defect of letter formation or spelling. Apart from want of sustained attention, reading did not appear to be affected.

These language disabilities receded very considerably during the last weeks of the patient's stay in hospital.

Formal psychometric testing gave an uneven picture. The vocabulary score was just below the mean, but this may have been in part due to the language disability. Performance on other Wechsler-Bellevue subtests suggested an I.Q. in the region of 110 . Despite his amnesia, the patient could repeat seven digits forwards and five backwards. He was unable to solve Weigl's test, sorting being inept and concrete. Performance on a Rorschach test was grossly perseverative and typical of an organic confusional state (Zangwill, 1945).

Air encephalography indicated a marked degree of cerebral atrophy: good filling of the ventricular system was obtained and the system was observed to be central. The lateral ventricles showed a marked degree of generalized symmetrical enlargement. There was a considerable increase in the size of the cortical subarachnoid channels and the basal cisterns were a little enlarged.

The patient was discharged to another institution four months after admission. Although the brain-stem disturbances and peripheral neuritis had improved appreciably, the underlying Korsakoff state remained unaltered.

Follow-up Studies. - The subsequent history of the patient is briefly as follows. He remained for four and a half months in hospital, during which time he made some progress, becoming gradually more lucid and less given to confabulation. He then discharged himself against the advice of his physicians. He had since remained at home and had not attempted to return to work.

The patient attended for a follow-up psychological examination 16 months after his discharge from the National Hospital. He was found to be lucid and approximately orientated in all spheres. He did not now misidentify persons. Although his memory for recent events was still grossly impaired, he no longer con- 
fabulated. There was, however, marked amnesia for events which had preceded the onset of the illness by some five to 10 years. The patient still lacked insight and denied his defect of memory. At the same time, he was considerably less euphoric than at the time of his discharge.

The patient's wife reported that he was strikingly unconcerned about his general situation but had otherwise shown no gross personality change.

In conversation, speech was fluent. Syntax and grammar were correct and choice of words appropriate. The patient could read aloud without hesitation or error. Nonetheless, he still appeared a little slow in grasping information and might still ask for questions to be repeated. He named objects correctly-with the exception of a drawing-pin which was miscalled a safety-pin. There was no apraxia.

On mental tests, it was found that the patient was unable to learn the Babcock sentence with 10 trials or to reproduce the gist of the cowboy story after two repetitions. On the other hand, pictures were described and interpreted in normal fashion and simpler block design tests adequately executed. Slight conceptual weakness was in evidence in Weigl's sorting test. Explanation of idioms and proverbs was now more satisfactory, although paraphasic and otherwise inappropriate responses might still be given. These contrasted strikingly with the patient's ability to describe pictures or to conduct an ordinary conversation.

Apart from the persistent minimal language derangement, the patient's state at this time appeared typical of a residual alcoholic Korsakoff psychosis.

Analysis of Language Disorder.-A number of interviews with the patient were recorded verbatim and analysed in some detail. A tape-recording of his conversation during the period of gross confusion was also made. The principal findings are as follows:

Misnaming.-In ordinary speech, names were used for the most part appropriately. On object-naming tests, on the other hand, the patient's responses were often grossly abnormal. The following examples may be given:

(19.7.56) Watch-Wrist-watch. Cigarette lighter-top hat lighter; asphalts and all that-tobacco accessory. Penknife-knife . . . jerry-knife, horse-knife as well. Corkscrew-an automatic accessory for bunging beers out of bottles. Pipe-pipe. You smoke it.

(31.7.56) Penknife-smoke affair. What is that? smoke button. Spanner-poetic collector. What is it used for ? Sharpening a knife. In and out, round the corner.

(9.8.56) Biro-a fountain pen but what we now call a box fountain pen. Box of matches-relief pens; matches of course. Bunch of keys-major keys, for use with any major fountain pen issued. I hope without keys. We call them vellum. I think that's what the name was when they were first put out.

Paraphasia and Neologisms.-A striking feature of the patient's speech was his tendency to use long and unusual words in quite inappropriate ways. Thus he referred to an interview as a "psychoanalogical categoreal examination " and gave as his reason for being in hospital that he was "suffering from expectorations of cholera attacks". In explaining a proverb, he referred quite irrelevantly to " an antagonistic outlook they've got on the affiliated amount of medical experience they possess". Occasionally, frank neologisms appeared in his speech, e.g. he used the word "cosmey" to denote a variety of wood and " stanch" to denote a meal.

These neologisms were fleeting and seldom, if ever, repeated.

Paraphasia was always much less apparent in ordinary conversation than under circumstances in which the patient was asked to define words, repeat phrases or explain proverbs, i.e. under conditions in which verbal reaction was relatively constrained. The patient appeared quite unaware of his paraphasias and made no attempt to correct them.

Perseveration and Discursiveness.-Perseveration both of words and ideas was frequent on verbal tests. More striking, however, was the patient's lack of thought control, expressing itself in flightiness, discursiveness, and a certain queer circumstantiality. Although his replies to direct questions were often brief and to the point, any task involving directed thinking provoked a long, discursive, and often totally incoherent flood of speech. This combination of paraphasia, discursiveness, and perseveration is well shown in the following examples drawn from his attempts to explain idioms and proverbs:

Safety First (9.8.56).- “I suppose it should mean to the ordinary person going up in education that it will mark your pen without any burn or flame or ink (perseveration from object-naming tests). You write on the paper but with safety without any accident that might occur afterwards."

(16.8.56) "It's an idea to make sure during any accident that is taking place. Light for the patient. First claim is made as the duty of the instruments used to make sure that the method is going to give you the results-perfect patient."

$A$ bird in the hand is worth two in the bush (9.8.56)."Well, a bird in the hand's a safety first giver (perseveration). It's a winner isn't it ? . . . . It's not birds it's something you wanted and effect desired and instruction given."

(16.8.56) "It means in the entirety of it, if you've got one in your hand you've got one. Two in the bush have their own leisure, freedom, patience-no contact with them. You could have one in each hand-would give you double the one."

Too many cooks spoil the broth (16.8.56)._- " Too many quits? Quits make an equal." (Proverb repeated): "Oh! Too many cooks spoil the broth. I'm good enough to do the cooking without your assistance. Just a plain statement that goes out from the ordinary cook. An antagonistic outlook they've got on the affiliated amount of medical experience they possess."

Pedantry and Witzelsucht.-There was at times a curious pedantry in speech. On one occasion, for 
instance, the patient named a rubber as " an india rubber or as you say in more obvious language an india rubber eraser". Equally, the combination of euphoria with lack of thought control gave rise on occasion to a definite Witzelsucht. Thus a corkscrew was called " an automatic accessory for bunging beers out of bottles ". He referred to the examiner on one occasion as "Dr. Caversham Caversham" (he had attended at a clinic known as the Caversham Centre) and remarked, à propos of being in hospital, that " The doctor said "The Guillotine Department for you'!"

The overall impression given by this patient's speech is difficult to convey. The flow of speech is exuberant, poorly controlled, discursive, paraphasic, and at times totally incoherent. Yet grammar and syntax are formally correct and there is no real nominal aphasia. The patient is much given to long and abstract wordsthe proper meanings of which were almost certainly unknown to him-and at times to a curious circumstantiality.

Bizarre trends are expressed from time to time and there is occasional Witzelsucht. The total picture is perhaps best described as a kind of confabulation within the sphere of language.

The language disorders which have been described could still be elicited when the patient was re-examined over a year later. At this time (February 27, 1958), the patient's speech was superficially normal, and in spite of amnesia and lack of insight he could scarcely have been called confused.

Safety First_-“' It's rather a lateral term which means it could apply to a host of things. A road for one thing."

Its meaning ?-" To my mind it means the primary thing in life is safety in any direction or walk of life, with traffic and so on."

Too many cooks spoil the broth-“" That's rather an old saying. It could apply to quite a lot of things. Too many people poking their noses into other people's business. Actually it's got nothing to do with cooking or broth."

A bird in the hand is worth two in the bush-."Well, I should imagine it emanates from a safety point of view really. I imagine it could emanate from a safety point or traffic. ..." (Proverb repeated): "It really emanates from a safety turn ... everything in hand, from a safety point of view. Your position wherever you are goingwalking, travelling, cycling, motoring-is fairly well preserved."

A rolling stone gathers no moss_-" I'm afraid I'm like one myself now. .. I'm just rolling about now. I'm used to an active life . . .non compos mentis."

Although at least one of these proverbs is adequately explained, evidence of paraphasia, perseveration, and flightiness is still present.

\section{Discussion}

The language disorder in this case is closely parallel to that described by Curran and Schilder (1935) in their cases of toxic and traumatic confusional states. Its most noteworthy features are mis- naming, paraphasia, discursiveness, perseveration, pedantry, and Witzelsucht. There was also an increased "speech drive" (logorrhoea) of the kind often reported to accompany sensory aphasia. The patient had no insight into the speech disorder and made no attempt to modify or correct his paraphasic errors. The language disorder receded very considerably in the later stages of the illness, despite the fact that the amnesic-confabulatory state improved much more gradually.

It is pertinent to inquire whether, and if so to what extent, this curious language disorder may be attributed to focal dysphasia. It is hardly necessary to point out that many features of this patient's speech are strongly suggestive of a jargon aphasia. Indeed we have records of cases of left temporal lobe lesion, without obvious defect of consciousness or memory, yet presenting almost exactly the same combination of logorrhoea, paraphasia, and perseveration. Further, the patient gave definite evidence of a mild comprehension defect, which in itself suggests low-grade central "word deafness". Although specific involvement of the left temporal lobe has certainly not been established, there is at any rate prima facie evidence of a dysphasic element in the syndrome.

Nonetheless, the disorganization of language in this case presents features which would appear to go beyond a disorder of speech as ordinarily conceived.

There would seem to be a basic loss of orderly and coherent thought and an irresponsible use of language akin to confabulation. Indeed the picture might suggest in exaggerated form that " approximate " use of language to which attention has been drawn in some patients after standard prefrontal leucotomy (Petrie, 1952; Tow, 1955). In these cases there is not uncommonly repetitiveness, alliteration, bizarre and inadequate formulation, and occasionally frank paraphasia (Tow, 1955). More striking, perhaps, is the parallel between the speech disorders we have described and those reported by Kleist (1934) in certain cases of occipito-temporal brain injury. Kleist believed the disorder in such cases to originate at a level antecedent to that of formulation and choice of words, i.e. at the pre-verbal level of thought. He therefore regarded it as a disorder of thought (" paralogia") rather than as a disturbance of speech (" paraphasia"). Although the relations between thought and speech are obscure, it would appear plausible to regard a derangement such as we have described as involving far-reaching disorganization of the thought processes.

The relation of the language disorder to concomitant defects in other spheres of psychological 
function deserves brief mention. As we have seen, Weinstein and Kahn (1952) place great emphasis on the part played by perceptual and motivational changes in the genesis of confusional paraphasia. As regards perception, there are undoubtedly a few cases in which it would appear plausible to refer misnaming to faulty visual perception. For the most part, however, objects are misnamed despite a correct grasp of their nature and use. It is also of course true that persons and situations are constantly misnamed in accordance with the prevailing disorientation, as in the cases described by Weinstein and Kahn (1952).

Yet it would seem improper to classify these responses as "paraphasic" in the ordinary sense of the term. Given the patient's limited and erroneous grasp of his environment, misnaming of persons and places is a psychologically consistent response. Unlike the language disorder which we have described, it is a constant feature of the Korsakoff psychosis.

We were unable to find much evidence of motivational changes governing speech errors in the present case. True, the patient made considerable reference in his talk to medical topics, even while denying that he was in hospital or in any way ill. This might suggest an underlying concern with issues relevant to the illness despite ostensible denial. The influence of previous personality make-up may also perhaps be traced in the patient's strong tendency to confabulation, Witzelsucht, and irresponsible speech. Further, it is plausible to suppose that motivational trends may find disguised and bizarre expression in confusional states, as in dreams and psychosis
(Paterson and Zangwill, 1944). Fuller analysis of "paralogia" in confusional states is obviously necessary before final conclusions can be drawn.

\section{Summary}

The occurrence of paraphasic speech disorders in organic confusional states is reviewed.

A case of Korsakoff's syndrome presenting a marked disturbance of language and thought is reported. This disorder is best described as a kind of confabulation within the sphere of language ("paralogia").

The relation of the language disorder to focal dysphasia and to concomitant defects in other spheres of psychological function is considered.

We wish to express our sincere gratitude to Dr. J. $\vec{\circ}$ Purdon Martin for his kind permission to study and record this case and for his advice in the preparation of this paper. We also wish to thank Dr. Isaac Sutton, Physician Superintendent, Friern Hospital, for his kindness in providing us with the follow-up information.

\section{REFERENCES} Brock, S., and Merwarth, H. R. (1957). A.M.A. Arch. Neurot

Critchley, M. (1953). The Parietal Lobes. Arnold, London.

Curran, F. J., and Schilder, P. (1935). J. nerv. ment. Dis., 82, 613.

Kleist, K. (1914). Münch. med. Wschr., 61, 8. 1934). Handbuch der ärtzlichen Erfahrungen im Weltkriege Vol. 4, p. 345. Barth, Leipsig.

Paterson, A. (1942). Lancet, 2, 717.

(1944). Proc. roy. Soc. Med., 37, 556.

, and Zangwill, O. L. (1944). Brain, 67, 54.

Petrie, A. (1952). Personality and the Frontal Lobes. Routledg

Tow, P. M. (1955). Personality Changes following Frontal Leucotomy. Oxford University Press, London.

Weinstein, E. A., and Kahn, R. L. (1952). A.M.A. Arch. Neurol Psychiat., 67, 72.

Zangwill, O. L.'(1945). J. ment. Sci., 91, 322. 